\title{
Intraperitoneal chemotherapy in the treatment of gastric cancer peritoneal metastases: an overview of common therapeutic regimens
}

\author{
Andreas Brandl ${ }^{1}$, Aruna Prabhu ${ }^{2}$ \\ ${ }^{1}$ Digestive Unit, Champalimaud Foundation, Lisbon, Portugal; ${ }^{2}$ Department of Surgical Oncology, Thangam Cancer Center, Namakkal, Tamil \\ Nadu, India \\ Contributions: (I) Conception and design: All authors; (II) Administrative support: None; (III) Provision of study materials or patients: None; (IV) \\ Collection and assembly of data: All authors; (V) Data analysis and interpretation: All authors; (VI) Manuscript writing: All authors; (VII) Final \\ approval of manuscript: All authors. \\ Correspondence to: Andreas Brandl, MD. Digestive Unit, Champalimaud Foundation, Av. de Brasília, Lisbon, Portugal. \\ Email: Andreas.Brandl8@gmail.com.
}

\begin{abstract}
Peritoneal metastasis (PM) have an incidence of 10-20\% in patients with gastric cancer (GC), and even up to $40 \%$ in patients with UICC Stage III GC. Due to the aggressive characteristic of adenocarcinoma of the stomach, GC is the third leading cause of cancer deaths worldwide. For GC with $\mathrm{PM}$, the treatment of choice is according to national and international guidelines systemic chemotherapy, combined with biologic therapy against specific receptor antigen in with overexpression, such as HER-2. Multimodal treatment regimens including intraperitoneal application of chemotherapy and cytoreductive surgery (CRS) have been investigated and established all over the world. Driven by pharmacological studies and thoughts considering the increased benefits of cytotoxic agents used in the abdominal cavity, several drugs and drug combinations are widely used. In order to standardize treatment protocols, it is crucial to differentiate between normothermic and hyperthermic intraperitoneal chemotherapy (NIPEC, HIPEC). The requirements of an ideal cytotoxic drug different obviously dependent on its application method. Because of their high molecular weight and lipophilic structure, taxanes, such as paclitaxel or docetaxel have a long intraperitoneal retention time and are commonly used in NIPEC, while platin derivates, such as carboplatin or oxaliplatin are known for their synergistic effect to heat and are chosen in HIPEC. This review aims to explore and summarize different intraperitoneal treatment regimens strictly evaluated by supporting evidence in an effort to consolidate many regimens to a few evidence-based treatment protocols that deserve further investigation and distribution. This analysis included all studies focusing on intraperitoneal chemotherapy: Phase II, Phase III trials and non-randomized retrospective trials of larger cohorts of patients with GC and established PM or risk of PM. Interestingly, the protocols for NIPEC are quite uniform, with less variation between the therapeutic components in contrast to the different HIPEC protocols. This difference might be explained by the divergent evolution of NIPEC and HIPEC, as the former exclusively originated in Japan, while HIPEC experienced a more multicentric evolution and distribution in the United States, Asia, Europe, and worldwide utilization today.
\end{abstract}

Keywords: Intraperitoneal chemotherapy; hyperthermic intraperitoneal chemotherapy (HIPEC); peritoneal metastasis (PM); gastric cancer (GC); treatment protocol

Submitted May 28, 2020. Accepted for publication Jun 27, 2020.

doi: 10.21037/jgo-2020-04

View this article at: http://dx.doi.org/10.21037/jgo-2020-04

@ Journal of Gastrointestinal Oncology. All rights reserved. 


\section{Introduction}

Gastric cancer (GC) is the third leading cause of cancer deaths worldwide, following only lung and colorectal cancer in overall mortality, as reported by GLOBOCAN 2018 data. GC has the fifth highest incidence among cancers, with 5.7\% of all new cases attributable to this disease. Approximately, one out of twelve oncological deaths are attributable to GC: more than one million new cases of GC are diagnosed, worldwide, each year (1). Among these patients, approximately 10-20\% present with synchronous peritoneal metastasis (PM) at time of primary surgery, and up to $40 \%$ in patients with extended disease, such as stage III GC (2). Patients with peritoneal metastasized GC have a poor prognosis, reaching a median overall survival of only 3 to 7 months (3).

The therapeutic options for these patients are limited and include palliative systemic chemotherapy and/or best supportive care, according to the recommendations of the NCCN guidelines (4). During the last two decades, multimodal treatment approaches including intraperitoneal chemotherapy with or without cytoreductive surgery (CRS) have been developed to improve overall survival in selected patients with GC. Unfortunately, due to its aggressive tumor biology compared to other peritoneal malignancies, such as ovarian cancer or appendiceal neoplasm, only a small subset of patients with GC benefit from CRS. Therefore, patient selection is of major importance for a beneficial treatment. In very selected patients (5-8\%), who present with good prognostic factors, (only localized $\mathrm{PM}$ or positive peritoneal cytology) and optimal treatment including systemic and IP chemotherapy with complete cytoreduction, long-term survival of more than ten years can be achieved $(5,6)$.

Treatment protocols, the choice of chemotherapeutic drugs, as well as the application method (intravenous versus intraperitoneal) varying all over the world, and lack standardization in many regions. In the Western World, in which hyperthermic intraperitoneal chemotherapy (HIPEC) including a combination of platin derivates with or without mitomycin C (MMC) are commonly used as the core component of the treatment of peritoneal surface malignancies (PSM). In contrast, Asian countries are using either repeated doses of normothermic intraperitoneal (IP) chemotherapy via IP port systems or a combination of both HIPEC and normothermic IP chemotherapy.

During the last ten years a novel method of IP chemotherapy application called Pressurized Intraperitoneal aerosol chemotherapy (PIPAC) has emerged with promising results and high pathologic regression rates in patients with peritoneal metastasized GC, and has spread all over the world (7). For the purpose of clarity, PIPAC was not subject of this review.

The aim of this review is to explore and summarize different IP protocols of liquid chemotherapy and application methods and compare them regarding their level of evidence. Ideally, this manuscript will consolidate many proposals into only a few treatment regimens.

\section{Pharmacological rationale of intraperitoneal chemotherapy}

One of the main benefits of IP chemotherapy is the reduced systemic uptake of anticancer drugs applied to the peritoneal cavity, which leads to a higher regional concentration with a prolonged direct exposure time to PM and free cancer cells. Due to the peritoneal-plasma barrier a much slower peritoneal drug clearance compared to the plasma clearance results. Hence, one of the important aspects of the ideal intraperitoneal cytotoxic agent is the molecular characteristics of the drug. Small molecular hydrophilic drugs such as MMC and cisplatin are rather quickly absorbed compared to large molecular lipophilic drugs as paclitaxel and docetaxel, which are slowly absorbed (8). Another important aspect for the right choice for HIPEC is the augmentation by hyperthermia.

In the 1970s, early experiments in the application of intraperitoneal chemotherapy were performed by the group of Robert Dedrick. Despite its various pharmacokinetic advantages, he recognized one potential disadvantage of this method, which was the limited penetration depth of the chemotherapeutic agents $(9,10)$. A few studies focused on this issue and found for example, paclitaxel, a penetration depth of $100-200 \mu \mathrm{m}$ from the surface of the tumor $(11,12)$.

In 1980, the first clinical application of HIPEC in a young patient with pseudomyxoma peritonei was published by Spratt et al. (13). The combination of hyperthermia and chemotherapy seems to be beneficial because of three reasons: (I) Hyperthermia itself has a selective cytotoxic effect on cancer cells (14); (II) hyperthermia enhances tissue perfusion and oxygenation and might therefore increase cytotoxic drug penetration (15); (III) several chemotherapeutic compounds, especially the platinum derivates (carboplatin, oxaliplatin) develop enhanced cytotoxicity through hyperthermia (16). 
Table 1 Treatment and outcome of studies focusing on patients with gastric cancer with positive cytology or peritoneal metastasis treated with intraperitoneal chemotherapeutic

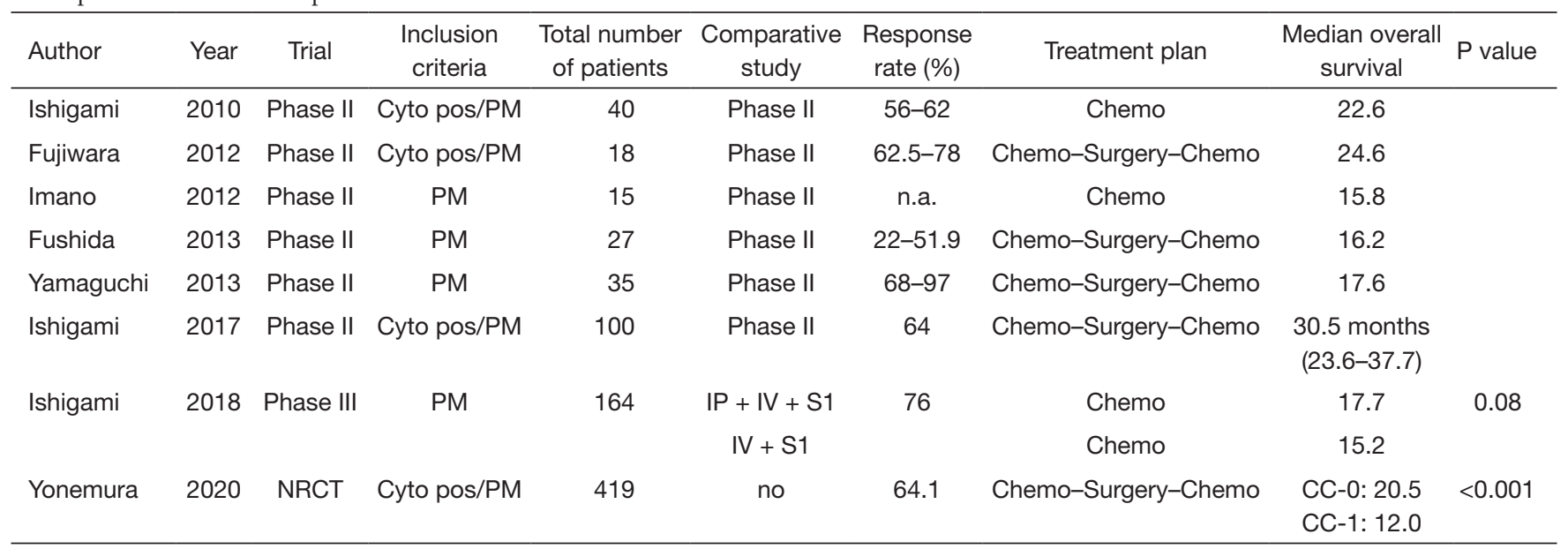

Cyto pos, positive cytology; PM, peritoneal metastasis; NRCT, non-randomized controlled trial; IP, intraperitoneally; IV, intravenously; S1, tegafur/gimeracil/oteracil; n.a., not available.

\section{Clinical rationale of intraperitoneal chemotherapy}

It is important to define different methodologies for IP chemotherapy applications, as one of the main differences is the utilization of heat. HIPEC is most commonly performed directly after extensive CRS in order to eliminate non-visible disease, such as free cancer cells. In the early postoperative phase, it was used less frequently months after the operation, and only most recently as a component of neo-adjuvant treatments. In nearly every case, HIPEC is applied through a heated circulatory machine in the operation room or on the intensive care unit.

A second possibility to treat with IP chemotherapy is through an IP port system as normothermic intraperitoneal chemotherapy (NIPEC). The peritoneal port system is usually introduced into the abdominal cavity under local anesthesia with its tip on the cul-de-sac of Douglas pouch. The port can be easily accessed to remove ascites (also for cytologic analysis) and for the application of cytotoxic drugs (17). This methodology can be used in an outpatient setting, as hospital admission is not necessary. Initially, one part of patients may receive treatment preoperatively. Treatment may continue after surgery as a combined bidirectional (systemic + IP) adjuvant regimen.

\section{IP chemotherapy}

In Asian countries, the placement of an IP port system for the repetitive usage of chemotherapeutic drugs is the most common practice. Usually, an intraperitoneal catheter and access port are implanted at the same time as staging laparoscopy, which is the gold standard diagnostic test to detect and document the size and distribution of PM in patients with GC. The catheter is placed in the small pelvis, and connected to a peritoneal access port, which is positioned in the subcutaneous fat tissue of the lower abdomen. The chemotherapeutic agent is dissolved in $500-1,000 \mathrm{~mL}$ of saline and is repeatedly infused through the IP port in the outpatient clinic. Peritoneal lavage cytology is available to monitor the efficacy of the treatment. The groups usually used a cis- or oxaliplatin containing intravenous chemotherapy combined with IP taxane, and oral Tegafur/ gimeracil/oteracil (S-1). Taxanes, such as paclitaxel have a long retention time within the peritoneal cavity due to their relatively high molecular weight, while augmentation by heat is not necessary (18). Systematic reviews of randomized controlled trials demonstrated the benefit of adjuvant IP chemotherapy in patients with advanced GC with PM or with positive cytology and high risk $(19,20)$.

Regarding the efficacy, Yonemura et al. could demonstrate a conversion rate from positive to negative cytology in patients with GC after neoadjuvant intraperitoneal-systemic chemotherapy (NIPS) of $69 \%$ in a total of 68 patients in 2012 (21). This treatment effect is associated with a low complication rate of $20.6 \%$ as reported by Emoto et al. in a series of 131 patients (22). The majority of the complications occurred either as an inflow obstruction or infection $(7.6 \%$ and $6.9 \%)$ during a median period of IP 
chemotherapy of 12.9 months (range, 0.8-61.5 months).

All RCT and non-randomized studies with more than 50 patients were included in our analysis. Treatment plan and oncologic outcome are illustrated in Table 1, details about the cytotoxic drug and regimen are shown in Table 2.

\section{Therapeutic (positive cytology and/or PM)}

In total, we could identify a total of 818 treated patients with PM or positive cytology of GC included in eight studies (5,23-29). Seven of eight groups used a singular IP drug (paclitaxel or docetaxel), while the group of Yonemura et al. used a combination of docetaxel and cisplatin. The most frequent dosage was for paclitaxel $20-80 \mathrm{mg} / \mathrm{m}^{2}$, docetaxel $30-60 \mathrm{mg} / \mathrm{m}^{2}$, and cisplatin $30 \mathrm{mg} / \mathrm{m}^{2}$. The IP treatment was always accompanied by systemic chemotherapy. S-1 took a core part in the treatment of every group with a dosage of $80 \mathrm{mg} / \mathrm{m}^{2}$ per day. Six of eight groups added chemotherapy intravenously to the therapeutic regimen, five of them applied paclitaxel $50 \mathrm{mg} / \mathrm{m}^{2}$, while the group of Yonemura et al. utilized a combination of $30 \mathrm{mg} / \mathrm{m}^{2}$ docetaxel with $30 \mathrm{mg} / \mathrm{m}^{2}$ cisplatin. Three weeks was the common cycle length used by seven groups with IP and IV application of chemotherapy at Day $1(n=7)$ and $8(n=5)$, accompanied with oral S-1 from Day 1-14, and a break during the last week. Fushida et al. used a cycle of four weeks with IP chemotherapy at Day 1 and 15, accompanied with oral S-1 from Day 1-14, and two weeks of break (26).

The only Phase III trial, so called PHOENIX-GC trial so far was performed by Ishigami et al. and was published in 2018 (29). A total of 183 patients with PM of GC were randomized either to a combination of $20 \mathrm{mg} / \mathrm{m}^{2}$ paclitaxel IP $+50 \mathrm{mg} / \mathrm{m}^{2}$ paclitaxel IV + oral $80 \mathrm{mg} / \mathrm{m}^{2} /$ day $\mathrm{S}-1$ or to systemic therapy only containing $50 \mathrm{mg} / \mathrm{m}^{2}$ paclitaxel IV + oral $80 \mathrm{mg} / \mathrm{m}^{2} /$ day S-1. The primary endpoint was overall survival after two years after study enrollment. Important to mention was the inclusion of mainly patients with advanced peritoneal disease, who would not qualify for cytoreduction. Advanced PM was also reflected in the ratio of patients with localized peritoneal spread (P1) of only $3 \%$. None of these patients were treated with surgery of the stomach nor of the PM. Impressively, the authors could demonstrate a median overall survival of patients in the IP arm of 17.7 months (95\% CI, 14.7 to 21.5 months) compared to 15.2 months (95\% CI, 12.8 to 21.8 months) in the systemic therapy $\operatorname{arm}(\mathrm{P}=0.080)$. The study failed to reach the level of significance. As a potential explanation of the negative trial the authors discussed, that the results were affected by (I) baseline imbalance (PCI and amount of ascites), (II) crossover between arms $(n=6)$, which were both in favor of the systemic chemotherapy group. Therefore, the clinical benefit of IP paclitaxel might be underestimated, which was strongly suggested by the explorative analysis performed by the authors.

In summary, normothermic IP chemotherapy showed promising results in several Phase II and non-randomized retrospective studies with median overall survival of 12 and 30.5 months in patients with GC and PM or positive cytology. The response rates in the bidirectional neoadjuvant setting were between $22 \%$ and $97 \%$ and support the concept of neoadjuvant intraperitoneal and systemic chemotherapy (NIPS). The only Phase III trial by Ishigami et al. was negative, with a clear trend in favor of IP chemotherapy in patients with advanced PM of GC.

The therapeutic protocol was consistent between the different groups and contained a cycle of three weeks (in $7 / 8$ studies). Also, IV application of paclitaxel $50 \mathrm{mg} / \mathrm{m}^{2}$ on Day 1 and 8 combined with IP docetaxel or paclitaxel accompanied by oral S-1 $80 \mathrm{mg} / \mathrm{m}^{2} /$ day on Day $1-14$.

\section{HIPEC}

Patients with positive cytology without PM seem to be a favorable group that benefit from HIPEC. This has been reported in small RCTs and several retrospective cohort analyses (30,31). Additional evidence favoring HIPEC in the patients with localized PM was delivered by a recent large propensity score adjusted analysis (CYTO-CHIP), which evaluated CRS alone vs. CRS and HIPEC in a French retrospective multicenter study. The authors could demonstrate a significant improved 3-year recurrence-free survival rate and overall survival of $20.4 \%$ vs. $5.9 \%(\mathrm{P}=0.001)$, and 18.8 vs. 12.1 months $(\mathrm{P}=0.005)$, respectively (32).

Today, there are several ongoing RCTs exploring the efficacy of HIPEC in patients with GC and PM in Germany (GASTRIPEC: NCT02158988), France (GASTRICHIP: NCT01882933), the Netherlands (PERISCOPE II: NCT03348150), and China (HIPEC-01: NCT02356276, N.N.: NCT02528110).

The inclusion criteria and the oncologic outcome of several randomized or non-randomized studies comparing surgical treatment \pm HIPEC are illustrated in Table 3. Every RCT and non-randomized studies with a minimum of 50 included patients were selected to be included in this table. Details of the different treatment protocols of HIPEC application are depicted in Tables 4,5. Different doses of the cytotoxic drugs were utilized as described in 
Table 2 Details of chemotherapeutic treatment protocols; Author names of studies with significant survival benefit of HIPEC are underlined

\begin{tabular}{|c|c|c|c|c|c|c|c|c|c|c|c|}
\hline Author & Year & Trial & $\begin{array}{c}\text { Inclusion } \\
\text { Criteria }\end{array}$ & $\begin{array}{l}\text { Number of } \\
\text { patients }\end{array}$ & $\begin{array}{c}\text { IP } \\
\text { cytotoxic } \\
\text { drug }\end{array}$ & $\begin{array}{l}\text { Dosage } \\
\left(\mathrm{mg} / \mathrm{m}^{2}\right)\end{array}$ & $\begin{array}{c}\text { Volume } \\
\text { (liters) }\end{array}$ & $\begin{array}{c}\text { Systemic } \\
\text { cytotoxic } \\
\text { drug }\end{array}$ & Dosage & $\begin{array}{c}\text { Cycle } \\
\text { length } \\
\text { (weeks) }\end{array}$ & Scheme \\
\hline \multirow{2}{*}{ Ishigami } & & & & & & & & PTX i.v. & $50 \mathrm{mg} / \mathrm{m}^{2}$ & & IV Day $1 \& 8$ \\
\hline & & & & & & & & & & & S-1 Day 1-14 \\
\hline \multirow[t]{3}{*}{ Fujiwara } & 2012 & Phase II & Cyto pos/PM & 18 & DOC & $40-60$ & 1 & S-1 oral & $80 \mathrm{mg} / \mathrm{m}^{2} /$ day & 3 & IP Day 1 \\
\hline & & & & & & & & & & & S-1 Day 1-14 \\
\hline & & & & & & & & & & & Day $15-21$ rest \\
\hline \multirow[t]{2}{*}{ Imano } & 2012 & Phase II & PM & 15 & PTX & 80 & 1 & S-1 oral & $80 \mathrm{mg} / \mathrm{m}^{2} /$ day & 3 & IP Day $1 \& 8$ \\
\hline & & & & & & & & & & & Day $15-21$ rest \\
\hline \multirow[t]{3}{*}{ Fushida } & 2013 & Phase II & PM & 27 & DOC & $35-50$ & 1 & S-1 oral & $80 \mathrm{mg} / \mathrm{m}^{2} /$ day & 4 & IP Day 1 \& 15 \\
\hline & & & & & & & & & & & S-1 Day 1-14 \\
\hline & & & & & & & & & & & Day $15-28$ rest \\
\hline \multirow[t]{3}{*}{ Yamaguchi } & 2013 & Phase II & PM & 35 & PTX & 20 & 1 & S-1 oral & $80 \mathrm{mg} / \mathrm{m}^{2} /$ day & 3 & IP Day $1 \& 8$ \\
\hline & & & & & & & & PTX i.v. & $50 \mathrm{mg} / \mathrm{m}^{2}$ & & IV Day 1 \& 8 \\
\hline & & & & & & & & & & & S-1 Day 1-14 \\
\hline \multirow[t]{4}{*}{ Ishigami } & 2018 & Phase III & PM & 164 & PTX & 20 & 0.5 & S-1 oral & $80 \mathrm{mg} / \mathrm{m}^{2} /$ day & 3 & IP Day $1 \& 8$ \\
\hline & & & & & & & & PTX i.v. & $50 \mathrm{mg} / \mathrm{m}^{2}$ & & IV Day $1 \& 8$ \\
\hline & & & & & & & & & & & S-1 Day 1-14 \\
\hline & & & & & & & & & & & Day $15-21$ rest \\
\hline \multirow[t]{4}{*}{ Yonemura } & 2020 & NRCT & Ctyo pos/PM & 419 & DOC & 30 & 0.5 & S-1 oral & $60 \mathrm{mg} / \mathrm{m}^{2} /$ day & 3 & IP Day 1 \\
\hline & & & & & $\mathrm{CIS}$ & 30 & & DOC i.v. & $30 \mathrm{mg} / \mathrm{m}^{2}$ & & IV Day 8 \\
\hline & & & & & & & & CIS i.v. & $30 \mathrm{mg} / \mathrm{m}^{2}$ & & S-1 Day 1-14 \\
\hline & & & & & & & & & & & Day $15-21$ rest \\
\hline
\end{tabular}

IP, intraperitoneally; NRCT, non-randomized controlled trial; Cyto pos, positive cytology; PM, peritoneal metastasis; i.v., intravenously; S1, tegafur/gimeracil/oteracil; PTX, paclitaxel; DOC, docetaxel; CIS, cisplatin. 


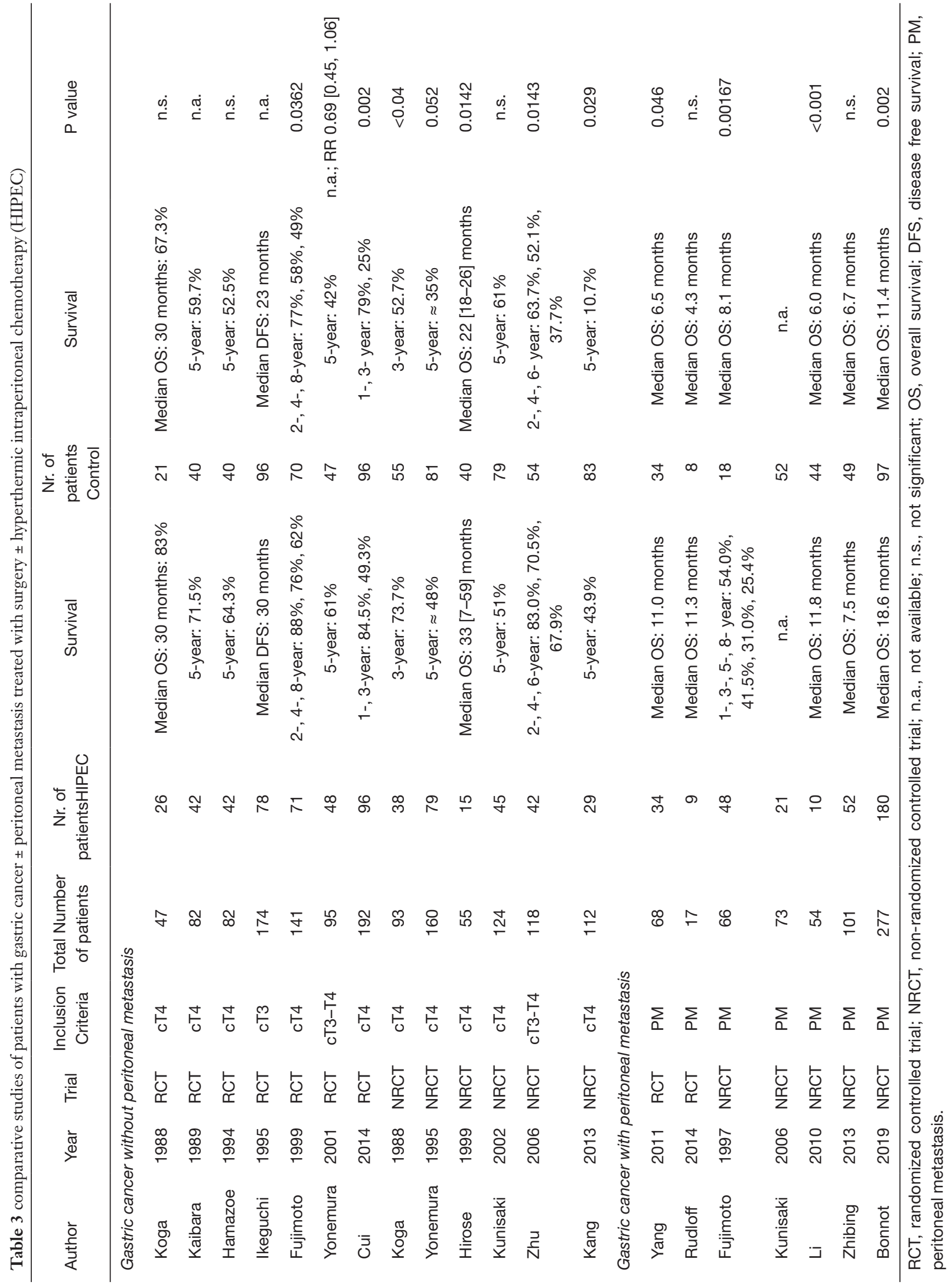


Table 4 Therapeutic details focused on hyperthermic intraperitoneal chemotherapy (HIPEC) application

\begin{tabular}{|c|c|c|c|c|c|c|c|c|c|c|c|}
\hline Author & Year & Trial & $\begin{array}{c}\text { Inclusion } \\
\text { criteria }\end{array}$ & $\begin{array}{c}\text { Total } \\
\text { number of } \\
\text { patients }\end{array}$ & $\begin{array}{l}\text { cytotoxic } \\
\text { drug }\end{array}$ & Dosage & $\begin{array}{l}\text { Volume } \\
\text { [liters] }\end{array}$ & $\begin{array}{c}\text { Concentration } \\
{[\mathrm{mg} / \mathrm{L}]}\end{array}$ & $\begin{array}{c}\text { HIPEC } \\
\text { duration } \\
\text { [min] }\end{array}$ & HIPEC $\left[{ }^{\circ} \mathrm{C}\right]$ & $\begin{array}{c}\text { HIPEC } \\
\text { technique }\end{array}$ \\
\hline Koga & 1988 & RCT & cT4 & 47 & MMC & $64-100 \mathrm{mg}$ & $10-12$ & $6.4-10.0$ & $50-60$ & 42 & closed \\
\hline Kaibara & 1989 & RCT & cT4 & 82 & MMC & n.a. & n.a. & n.a. & n.a. & n.a. & closed \\
\hline Ikeguchi & 1995 & RCT & cT3 & 174 & MMC & $80-100 \mathrm{mg} / \mathrm{m}^{2}$ & $8-10$ & $12.8-20$ & n.a. & $40-42$ & n.a. \\
\hline Fujimoto $^{\&}$ & 1999 & $\mathrm{RCT}$ & cT4 & 141 & MMC & $10 \mathrm{mg} / \mathrm{L}$ & $3-4$ & 10 & 120 & $43-44$ & closed \\
\hline \multirow[t]{2}{*}{ Yonemura } & 2001 & RCT & сT3-T4 & 95 & CIS & $300 \mathrm{mg}$ & $6-8$ & $37.5-50$ * & n.a. & $42-43$ & open \\
\hline & & & & & MMC & $30 \mathrm{mg}$ & & $3.75-5.0$ * & & & \\
\hline Koga ${ }^{\&}$ & 1988 & NRCT & cT4 & 93 & MMC & $64-100 \mathrm{mg}$ & $10-12$ & $6.4-10.0$ & $50-60$ & 42 & \\
\hline \multirow[t]{2}{*}{ Yonemura } & 1995 & NRCT & cT4 & 160 & MMC & $30 \mathrm{mg}$ & 8 & 3.75 & 60 & $41.5-43.5$ & open \\
\hline & & & & & CIS & $300 \mathrm{mg}$ & & 37.5 & & & \\
\hline \multirow[t]{3}{*}{ Hirose $^{\&}$} & 1999 & NRCT & cT4 & 55 & MMC & $20 \mathrm{mg}$ & $4-5$ & $4-5$ & 50 & $41-44.5$ & open \\
\hline & & & & & CIS & $100 \mathrm{mg}$ & & $20-25$ & & & \\
\hline & & & & & Etoposide & $100 \mathrm{mg}$ & & $20-25$ & & & \\
\hline Kunisaki & 2002 & NRCT & cT4 & 124 & MMC & $15 \mathrm{mg}$ & $5-6$ & $2.5-3$ & 40 & $42-43$ & open \\
\hline \multirow{2}{*}{ Kang $^{\&}$} & & & & & CIS & $30 \mathrm{mg} / \mathrm{L}$ & & 30 & & & \\
\hline & & & & & Etoposide & $20 \mathrm{mg} / \mathrm{L}$ & & 20 & & & \\
\hline \multicolumn{12}{|c|}{ Gastric cancer with peritoneal metastasis } \\
\hline \multirow[t]{2}{*}{ Yang $^{\&}$} & 2011 & $\mathrm{RCT}$ & PM & 68 & MMC & $5 \mathrm{mg} / \mathrm{L}$ & 6 & 5 & $60-90$ & $43 \pm 0.5$ & open \\
\hline & & & & & CIS & $20 \mathrm{mg} / \mathrm{L}$ & & 20 & & & \\
\hline Rudloff & 2014 & RCT & PM & 17 & Oxaliplatin & $460 \mathrm{mg} / \mathrm{m}^{2}$ & n.a. & n.a. & 30 & 41 & closed \\
\hline Fujimoto $^{\&}$ & 1997 & NRCT & PM & 66 & MMC & $10 \mathrm{mg} / \mathrm{L}$ & $3-4$ & 10 & 120 & $43-44$ & closed \\
\hline \multirow[t]{3}{*}{ Kunisaki } & 2006 & NRCT & PM & 73 & MMC & $30 \mathrm{mg}$ & $5-6$ & $5-6$ & 40 & $42-43$ & n.a. \\
\hline & & & & & CIS & $300 \mathrm{mg}$ & & $50-60$ & & & \\
\hline & & & & & Etoposide & $300 \mathrm{mg}$ & & $50-60$ & & & \\
\hline \multirow[t]{2}{*}{$\mathrm{Li}^{\&}$} & 2010 & NRCT & PM & 54 & MMC & $5 \mathrm{mg} / \mathrm{L}$ & $5-6$ & 5 & 60 & $43.0 \pm 1.0$ & open \\
\hline & & & & & CIS & 50 mg/L & & 50 & & & \\
\hline
\end{tabular}

Table 4 (continued) 
Table 4 (continued)

\begin{tabular}{|c|c|c|c|c|c|c|c|c|c|c|c|}
\hline Author & Year & Trial & $\begin{array}{c}\text { Inclusion } \\
\text { criteria }\end{array}$ & $\begin{array}{c}\text { Total } \\
\text { number of } \\
\text { patients }\end{array}$ & $\begin{array}{l}\text { cytotoxic } \\
\text { drug }\end{array}$ & Dosage & $\begin{array}{l}\text { Volume } \\
\text { [liters] }\end{array}$ & $\begin{array}{l}\text { Concentration } \\
{[\mathrm{mg} / \mathrm{L}]}\end{array}$ & $\begin{array}{c}\text { HIPEC } \\
\text { duration } \\
\text { [min] }\end{array}$ & HIPEC $\left[{ }^{\circ} \mathrm{C}\right]$ & $\begin{array}{c}\text { HIPEC } \\
\text { technique }\end{array}$ \\
\hline \multirow[t]{4}{*}{ Bonnot ${ }^{\&}$} & 2019 & NRCT & PM & 277 & $\mathrm{MMC}^{+}$ & $30-50 \mathrm{mg} / \mathrm{m}^{2}$ & n.a. & n.a. & $60-120$ & $41-43$ & $\begin{array}{l}\text { Open or } \\
\text { closed }\end{array}$ \\
\hline & & & & & $\mathrm{CIS}^{+}$ & $50-100 \mathrm{mg} / \mathrm{m}^{2}$ & & & $60-90$ & $42-43$ & \\
\hline & & & & & $\mathrm{DOX}^{+}$ & $15 \mathrm{mg} / \mathrm{m}^{2}$ & & & $60-90$ & $42-43$ & \\
\hline & & & & & Oxaliplatin ${ }^{+}$ & $300-460 \mathrm{mg} / \mathrm{m}^{2}$ & & & 30 & 43 & \\
\hline
\end{tabular}

\&, studies with significant survival benefit of HIPEC; *, calculated; ${ }^{+}$, several combinations; ", on postoperative day 1 \& 4. RCT, randomized controlled trial; NRCT, non-randomized controlled trial; CIS, cisplatin; PM, peritoneal metastasis; MMC, mitomycin C; n.a., not available; DOX, Doxorubicin;

Table 5 Therapeutic details of ongoing RCTs on hyperthermic intraperitoneal chemotherapy (HIPEC) application

\begin{tabular}{|c|c|c|c|c|c|c|c|c|c|c|c|}
\hline $\begin{array}{l}\text { Principle } \\
\text { Investigator } \\
\text { Indication }\end{array}$ & Acronym & Randomization & $\begin{array}{l}\text { Inclusion } \\
\text { criteria }\end{array}$ & $\begin{array}{l}\text { Planned } \\
\text { Nr of } \\
\text { patients }\end{array}$ & $\begin{array}{l}\text { cytotoxic } \\
\text { drug }\end{array}$ & $\begin{array}{c}\text { Dosage, } \\
\mathrm{mg} / \mathrm{m}^{2}\end{array}$ & $\begin{array}{l}\text { Volume } \\
\text { [liters] }\end{array}$ & $\begin{array}{l}\text { Concentration } \\
\qquad[\mathrm{mg} / \mathrm{L}]\end{array}$ & $\begin{array}{c}\text { HIPEC } \\
\text { duration } \\
\text { [min] }\end{array}$ & $\begin{array}{c}\text { HIPEC } \\
{\left[{ }^{\circ} \mathrm{C}\right]}\end{array}$ & $\begin{array}{c}\text { HIPEC } \\
\text { technique }\end{array}$ \\
\hline \multicolumn{12}{|l|}{ Ongoing RCTs } \\
\hline \multirow[t]{2}{*}{$\begin{array}{l}\text { Rau } \\
\text { NCT02158988 }\end{array}$} & GASTRIPEC & $\mathrm{CRS} \pm \mathrm{HIPEC}$ & PM & 180 & MMC & 15 & 5 & 5.4 & 60 & $42-43$ & $\begin{array}{l}\text { Open or } \\
\text { closed }\end{array}$ \\
\hline & & & & & CIS & 75 & & 27.2 & & & \\
\hline \multirow[t]{2}{*}{$\begin{array}{l}\text { Glehen } \\
\text { NCT01882933 }\end{array}$} & GASTRICHIP & $\begin{array}{l}\text { Surgery } \pm \\
\text { HIPEC }\end{array}$ & $\begin{array}{l}\text { T4 or Cyto } \\
\text { pos }\end{array}$ & 367 & Oxaliplatin & 250 & $2 \mathrm{~L} / \mathrm{m}^{2}$ & 125 & 30 & $42-43$ & $\begin{array}{l}\text { Open or } \\
\text { closed }\end{array}$ \\
\hline & & & & & & 50 & & & & & \\
\hline \multirow[t]{2}{*}{$\begin{array}{l}\text { van Sandick } \\
\text { NCT03348150 }\end{array}$} & $\begin{array}{c}\text { PERISCOPE } \\
\text { II }\end{array}$ & $\begin{array}{c}\text { CRS + HIPEC } \\
\text { vs. systemic } \\
\text { chemo }\end{array}$ & $\begin{array}{l}\text { Cyto pos or } \\
\mathrm{PM}(\mathrm{PCl}<7)\end{array}$ & 106 & Oxaliplatin & 460 & n.a. & n.a. & 30 & 42 & Open \\
\hline & & & & & DOC & 50 & & & 90 & 37 & \\
\hline \multirow[t]{2}{*}{$\begin{array}{l}\text { Cui } \\
\text { NCT02356276 }\end{array}$} & HIPEC-01 & $\begin{array}{c}\text { Surgery } \pm \\
\text { HIPEC (2 times) }\end{array}$ & сT3-T4 & 584 & PTX & 1st 75 & $3-4$ & $30-40$ & 60 & 43 & n.a. \\
\hline & & & & & & 2nd & & $40-53.3$ & & & \\
\hline \multirow[t]{2}{*}{ NCT02528110 } & n.a. & $\begin{array}{l}\text { Surgery } \pm \\
\text { HIPEC }\end{array}$ & сT3-T4 & 100 & PTX & 75 & $3-4$ & $30-40$ & 60 & 43 & n.a. \\
\hline & & & & & 5-FU & 15 & & $6-8$ & & & \\
\hline
\end{tabular}

HIPEC, hyperthermic intraperitoneal chemotherapy; Cyto pos, positive cytology; PM, peritoneal metastasis; CIS, cisplatin; MMC, mitomycin C; n.a., not available; DOC, docetaxel; PTX, paclitaxel; 5-FU, Fluorouracil. 
the manuscripts. For the purpose of a better comparison, doses were unified in concentrations $[\mathrm{mg} / \mathrm{L}]$ using regional mean body surface areas as an assumption. Therefore, $1.81 \mathrm{~m}^{2}$ was selected according to a Dutch study of 1,868 participants representing the European and Northern American population, and $1.60 \mathrm{~m}^{2}$ according to the results of a Chinese study about 3,951 participants representing patients from Asian trials $(33,34)$.

The information of the study of Kaibara et al. (1989) was extracted from the abstract only, as the full manuscript was not online accessible (35).

\section{Prophylactic (advanced GC and/or Cytology positive)}

In total there are 17 studies; 13 of them were published, while four are ongoing RCTs focused on the efficacy of HIPEC in prophylactic indication for patients with advanced GC or positive cytology at any stage of treatment (35-48). The French GASTRICHIP trial is the only nonAsian study for this indication.

Eight groups used a singular IP cytotoxic agent (MMC or Oxaliplatin or Paclitaxel), six used two (a combination of Cisplatin, MMC, Paclitaxel and Fluorouracil), and three publications reported three cytotoxic agents (MMC + Cisplatin + Etoposide) used for HIPEC. The most common concentrations were: MMC 2.5-17.5 mg/L $(\mathrm{n}=11)$, Cisplatin $20-50 \mathrm{mg} / \mathrm{L}(\mathrm{n}=7)$, Oxaliplatin $125 \mathrm{mg} / \mathrm{L}$ $(\mathrm{n}=1)$, Paclitaxel 30-53.3 $\mathrm{mg} / \mathrm{L}(\mathrm{n}=2)$, Fluorouracil 6-250 mg/L ( $\mathrm{n}=2$ ), and Etoposide $20-30 \mathrm{mg} / \mathrm{L}(\mathrm{n}=3)$. The HIPEC duration was between 50 and 120 minutes, with the exception of Oxaliplatin, which was used for 30 minutes only. The HIPEC temperature was $40.0-44.5^{\circ} \mathrm{C}$ with the usage of both open or closed circulation techniques.

Regarding the highest level of evidence, two RCTs showed an overall survival benefit in patients with advanced GC using either MMC $10 \mathrm{mg} / \mathrm{L}$ for 120 minutes with $43-44{ }^{\circ} \mathrm{C}$ or Cisplatin $35 \mathrm{mg} / \mathrm{L}$ in combination with Fluorouracil $250 \mathrm{mg} / \mathrm{L}$ for 90 minutes with $41-43{ }^{\circ} \mathrm{C}$ in a closed circulation system.

In total, four non-randomized controlled trials demonstrated an increased overall survival using either the triplet combination MMC 4-5 or $10 \mathrm{mg} / \mathrm{L}$, Cisplatin 20-25 or $30 \mathrm{mg} / \mathrm{L}$, Etoposide $20-25 \mathrm{mg} / \mathrm{L}$ or MMC $5 \mathrm{mg} / \mathrm{L}$, Cisplatin $50 \mathrm{mg} / \mathrm{L}$ or MMC $6.4-10 \mathrm{mg} / \mathrm{L}$ monotherapy for $50-60$ minutes with $41-44.5^{\circ} \mathrm{C}$ in an open or closed system.

\section{Therapeutic (PM)}

In total, nine studies were included in this analysis including two European ongoing RCT (GASTRIPEC, PERISCOPE II) $(32,44,49-53)$. Three groups used a singular cytotoxic agent (MMC or Cisplatin or Oxaliplatin), four used two drugs (MMC + Cisplatin or Oxaliplatin + Docetaxel), and one group used a combination of MMC + Cisplatin + Etoposide. The drug concentrations ranged between: $\mathrm{MMC}$ 5-6 mg/L ( $\mathrm{n}=5)$, Cisplatin 20-60 mg/L ( $\mathrm{n}=4)$, Oxaliplatin $125 \mathrm{mg} / \mathrm{L}(\mathrm{n}=1)$, Docetaxel $50 \mathrm{mg} / \mathrm{m}^{2}(\mathrm{n}=1)$, and Etoposide $50-60 \mathrm{mg} / \mathrm{L}(\mathrm{n}=1)$. The duration of HIPEC was between 30 and 120 minutes using a temperature between $42-44{ }^{\circ} \mathrm{C}$ with both circulation techniques (open and closed).

The RCT from Yang et al., demonstrated a survival benefit for patients treated with HIPEC using MMC $5 \mathrm{mg} / \mathrm{L}$ + Cisplatin $20 \mathrm{mg} / \mathrm{L}$ for $60-90$ minutes with $43 \pm 0.5^{\circ} \mathrm{C}(11.0$ vs. 6.5 months, $\mathrm{P}=0.046$ ) (49).

Three non-randomized comparative trials were able to show an increased overall survival using either MMC $10 \mathrm{mg} /$ $\mathrm{L}$ as monotherapy for 120 minutes with $43-44{ }^{\circ} \mathrm{C}$ or the combination of MMC $5 \mathrm{mg} / \mathrm{L}$ + Cisplatin $50 \mathrm{mg} / \mathrm{L}$ for 60 minutes with $43.0 \pm 1.0^{\circ} \mathrm{C}(51,52)$. The CYTOCHIP study from Bonnot et al. could not be analyzed regarding the HIPEC regimen, due to the variety of different HIPEC regimens, which have been included in this multicenter study (32).

\section{Translational research}

There are only few reports about animal studies regarding PM of GC. The clinical application of IP chemotherapy as it is commonly used today in several expert centers, was developed with a relatively low complication rate and low morbidity. In combination with an aggressive disease in which the patients usually face a median overall survival of few months and the additionally lack of therapeutic alternatives, the clinical implementation of IP chemotherapy progressed without a broad fundament of preclinical models. This situation is similar to other diseases addressed by HIPEC, such as PM of colorectal cancer. The only preclinical studies were conducted in Japan, where the incidence of GC is very high, and innovative therapeutic options were eagerly explored.

\section{Animal model and chemosensitivity}

In 2003, Nakanishi et al. demonstrated an increased survival of nude mice, which have been intraperitoneally inoculated with a green fluorescence protein (GFP)-tagged human GC cell line (GCIY) and treated with oral S-1 at a dose of $20 \mathrm{mg} / \mathrm{kg} /$ day (54).

In 2005, Yonemura et al. examined in vitro chemosensitivity 


\begin{tabular}{l|l|l|l|} 
Drug & \multicolumn{1}{l}{ Dose } & Application & Day \\
\hline S-1 & $80 \mathrm{mg} / \mathrm{m}^{2}$ per day & Oral, twice daily & $1-14$ \\
\hline $\begin{array}{l}\text { Paclitaxel } \\
\text { or } \\
\text { Docetaxel }\end{array}$ & $20 \mathrm{mg} / \mathrm{m}^{2}$ & Intraperitoneal & $1 \& 8$ \\
\hline Paclitaxel & $50-50 \mathrm{mg} / \mathrm{m}^{2}$ & intraperitoneal & $1 \& 8$ \\
\hline
\end{tabular}

Figure 1 IP chemotherapy (NIPEC) regimen.

\begin{tabular}{|c|c|c|c|}
\hline Drug & Dose & Duration & Temperature \\
\hline Mitomycin C & 10 mg/L & 60 or 120 minutes & $43^{\circ} \mathrm{C}$ \\
\hline
\end{tabular}

Suggestion II: Combined Therapy

\begin{tabular}{l|l|l|l}
\hline Drug & \multicolumn{1}{|l}{ Dose } & Duration & Temperature \\
\hline Mitomycin C & $5 \mathrm{mg} / \mathrm{L}$ & \multirow{2}{*}{60 or 90 minutes } & $43^{\circ} \mathrm{C}$ \\
\hline Cisplatin & $20-50 \mathrm{mg} / \mathrm{L}$ & & \\
\hline
\end{tabular}

Suggestion III: Combined Therapy

\begin{tabular}{l|l|l|l}
\hline Drug & \multicolumn{1}{l}{ Dose } & \multicolumn{1}{c}{ Duration } & Temperature \\
\hline Cisplatin & $32 \mathrm{mg} / \mathrm{L}$ & \multirow{2}{*}{90 minutes } & $43^{\circ} \mathrm{C}$ \\
\cline { 1 - 2 } Fluorouracil & $250 \mathrm{mg} / \mathrm{L}$ & & \\
\hline
\end{tabular}

Figure 2 Hyperthermic intraperitoneal chemotherapy (HIPEC) regimen.

using a collagen-gel method on 165 primary GCs, and the efficacy of intraperitoneal chemotherapeutic drugs in nude mice, which were intraperitoneally inoculated by $10^{7}$ MKN-45-P cells (55). The authors could conclude, that the combination of oral S-1 with intraperitoneally cisplatin, fluorouracil, docetaxel or carboplatin improved overall survival in this animal model.

\section{Patient-derived Xenograft (PDX) model}

Today, there are no reports about orthotopic PDX models of PM of GC so far.

\section{Conversion surgery (CS)}

The term CS is defined as surgical treatment aimed at curative resection in patients with positive cytology or limited PM, that responded significantly to neoadjuvant chemotherapeutic regimens. The rate of patients with positive cytology, that transformed to negative after NIPS or NIPEC was reported between $69 \%$ and $78 \%$, and even after systemic chemotherapy alone conversion rates in patients with positive cytology or PM of $66 \%$ or $15 \%$ were reported, respectively $(21,29,56)$. CS has been proved to be safe, and seems to prolong overall survival compared to patients without CS, as a study of Ishigami et al. demonstrated (30.5 vs. 14.3 months) (28). The question whether the survival benefit is a result of the surgical intervention or solely the result of the selection of patients with a potentially better tumor biology, remains until the conduction of a randomized controlled trial unanswered. The data of the REGATTA trial showed, that surgical treatment of the primary without removal of metastasis prior chemotherapy and therefore irrespective of any response evaluation do not add a survival benefit to the patients (57).

\section{Standardization of protocols}

The standardization of treatment protocols is generally a challenging task. Especially due to the lack of translational studies, a simplification of treatment protocols can only be suggested. In order to define a standard of therapy, translational research including chemosensitivity testing, evaluation of HIPEC application, etc. have to be conducted using animal, PDX models, and clinical trials.

Obviously, the treatment protocols of HIPEC differed significantly. Three out of five trials favoring HIPEC in the prophylactic setting contained the monotherapy with MMC 10 $\mathrm{mg} / \mathrm{L}$, as represented in Suggestion I. Suggestion III originates from the largest positive RCT conducted by Cui et al. (41).

Nevertheless, our review explored the most commonly used IP protocols for the treatment of patients with PM of GC and summarizes the results as follows:

\section{IP chemotherapy (NIPEC)}

Indication: positive peritoneal cytology or peritoneal metastasis of gastric cancer.

Application: treatment: Day 1-14; Resting: Day 15-21 (Figure 1).

\section{HIPEC}

Indication: Positive peritoneal cytology or cT3-4 or peritoneal metastasis.

Suggestion I-III: Figure 2. 


\section{Acknowledgments}

Funding: None.

\section{Footnote}

Provenance and Peer Review: This article was commissioned by the Guest Editors (Paul H. Sugarbaker and Kurt Van der Speeten) for the focused issue "Intraperitoneal Chemotherapy for Peritoneal Metastases: HIPEC, EPIC, NIPEC, PIPAC and More" published in fournal of Gastrointestinal Oncology. This article has undergone external peer review.

Conflicts of Interest: Both authors have completed the ICMJE uniform disclosure form (available at http:// dx.doi.org/10.21037/jgo-2020-04). The focused issue was sponsored by the Peritoneal Surface Oncology Group International (PSOGI). The authors have no other conflicts of interest to declare.

Ethical Statement: The authors are accountable for all aspects of the work in ensuring that questions related to the accuracy or integrity of any part of the work are appropriately investigated and resolved.

Open Access Statement: This is an Open Access article distributed in accordance with the Creative Commons Attribution-NonCommercial-NoDerivs 4.0 International License (CC BY-NC-ND 4.0), which permits the noncommercial replication and distribution of the article with the strict proviso that no changes or edits are made and the original work is properly cited (including links to both the formal publication through the relevant DOI and the license). See: https://creativecommons.org/licenses/by-nc-nd/4.0/.

\section{References}

1. Bray F, Ferlay J, Soerjomataram I, et al. Global cancer statistics 2018: GLOBOCAN estimates of incidence and mortality worldwide for 36 cancers in 185 countries. CA Cancer J Clin 2018;68:394-424.

2. Roviello F, Caruso S, Neri A, et al. Treatment and prevention of peritoneal carcinomatosis from gastric cancer by cytoreductive surgery and hyperthermic intraperitoneal chemotherapy: overview and rationale. Eur J Surg Oncol 2013;39:1309-16.

3. Yonemura Y, Elnemr A, Endou Y, et al. Multidisciplinary therapy for treatment of patients with peritoneal carcinomatosis from gastric cancer. World J Gastrointest Oncol 2010;2:85-97.

4. Ajani JA, Bentrem DJ, Besh S, et al. Gastric cancer, version 2.2013: featured updates to the NCCN Guidelines. J Natl Compr Canc Netw 2013;11:531-46.

5. Yonemura Y, Prabhu A, Sako S, et al. Long Term Survival after Cytoreductive Surgery Combined with Perioperative Chemotherapy in Gastric Cancer Patients with Peritoneal Metastasis. Cancers (Basel) 2020;12:116.

6. Brandl A, Yonemura Y, Glehen O, et al. Long-term survival in patients with peritoneal metastasized gastric cancer treated with cytoreductive surgery and HIPEC: A multi-institutional cohort from PSOGI. J Clin Oncol 2020;38:390.

7. Ellebæk SB, Graversen M, Detlefsen S, et al. Pressurized intraperitoneal aerosol chemotherapy (PIPAC) of peritoneal metastasis from gastric cancer: a descriptive cohort study. Clin Exp Metastasis 2020;37:325-32.

8. Markman M, Rowinsky E, Hakes T, et al. Phase I trial of intraperitoneal taxol: a Gynecoloic Oncology Group study. J Clin Oncol 1992;10:1485-91.

9. Dedrick RL, Myers CE, Bungay PM, et al. Pharmacokinetic rationale for peritoneal drug administration in the treatment of ovarian cancer. Cancer Treat Rep 1978;62:1-11.

10. Dedrick RL. Theoretical and experimental bases of intraperitoneal chemotherapy. Semin Oncol 1985;12:1-6.

11. Kamei T, Kitayama J, Yamaguchi H, et al. Spatial distribution of intraperitoneally administrated paclitaxel nanoparticles solubilized with poly (2-methacryloxyethyl phosphorylcholine-co n-butyl methacrylate) in peritoneal metastatic nodules. Cancer Sci 2011;102:200-5.

12. Sugarbaker PH, Van der Speeten K. Surgical technology and pharmacology of hyperthermic perioperative chemotherapy. J Gastrointest Oncol 2016;7:29-44.

13. Spratt JS, Adcock RA, Muskovin M, et al. Clinical delivery system for intraperitoneal hyperthermic chemotherapy. Cancer Res 1980;40:256-60.

14. Hildebrandt $\mathrm{B}$, Wust $\mathrm{P}$, Ahlers $\mathrm{O}$, et al. The cellular and molecular basis of hyperthermia. Crit Rev Oncol Hematol 2002;43:33-56.

15. Los G, Sminia P, Wondergem J, et al. Optimisation of intraperitoneal cisplatin therapy with regional hyperthermia in rats. Eur J Cancer 1991;27:472-7.

16. Raaphorst GP, Yang DP. The evaluation of thermal cisplatin sensitization in normal and XP human cells using mild hyperthermia at 40 and 41 degrees C. Anticancer Res 
2005;25:2649-53.

17. Yonemura Y, Bandou E, Sawa T, et al. Neoadjuvant treatment of gastric cancer with peritoneal dissemination. Eur J Surg Oncol 2006;32:661-5.

18. Mohamed F, Sugarbaker PH. Intraperitoneal taxanes. Surg Oncol Clin N Am 2003;12:825-33.

19. Kobayashi D, Kodera Y. Intraperitoneal chemotherapy for gastric cancer with peritoneal metastasis. Gastric Cancer 2017;20:111-21.

20. Feingold PL, Kwong ML, Davis JL, et al. Adjuvant intraperitoneal chemotherapy for the treatment of gastric cancer at risk for peritoneal carcinomatosis: A systematic review. J Surg Oncol 2017;115:192-201.

21. Yonemura Y, Elnemr A, Endou Y, et al. Effects of neoadjuvant intraperitoneal/systemic chemotherapy (bidirectional chemotherapy) for the treatment of patients with peritoneal metastasis from gastric cancer. Int J Surg Oncol 2012;2012:148420.

22. Emoto S, Ishigami H, Hidemura A, et al. Complications and management of an implanted intraperitoneal access port system for intraperitoneal chemotherapy for gastric cancer with peritoneal metastasis. Jpn J Clin Oncol 2012;42:1013-9.

23. Ishigami H, Kitayama J, Kaisaki S, et al. Phase II study of weekly intravenous and intraperitoneal paclitaxel combined with S-1 for advanced gastric cancer with peritoneal metastasis. Ann Oncol 2010;21:67-70.

24. Fujiwara Y, Takiguchi S, Nakajima K, et al. Intraperitoneal docetaxel combined with S-1 for advanced gastric cancer with peritoneal dissemination. J Surg Oncol 2012;105:38-42.

25. Imano M, Yasuda A, Itoh T, et al. Phase II study of single intraperitoneal chemotherapy followed by systemic chemotherapy for gastric cancer with peritoneal metastasis. J Gastrointest Surg 2012;16:2190-6.

26. Fushida S, Kinoshita J, Kaji M, et al. Phase I/II study of intraperitoneal docetaxel plus S-1 for the gastric cancer patients with peritoneal carcinomatosis. Cancer Chemother Pharmacol 2013;71:1265-72.

27. Yamaguchi H, Kitayama J, Ishigami H, et al. A phase 2 trial of intravenous and intraperitoneal paclitaxel combined with S-1 for treatment of gastric cancer with macroscopic peritoneal metastasis. Cancer 2013;119:3354-8.

28. Ishigami H, Yamaguchi H, Yamashita H, et al. Surgery after intraperitoneal and systemic chemotherapy for gastric cancer with peritoneal metastasis or positive peritoneal cytology findings. Gastric Cancer 2017;20:128-34.

29. Ishigami H, Fujiwara Y, Fukushima R, et al. Phase III Trial
Comparing Intraperitoneal and Intravenous Paclitaxel Plus S-1 Versus Cisplatin Plus S-1 in Patients With Gastric Cancer With Peritoneal Metastasis: PHOENIX-GC Trial. J Clin Oncol 2018;36:1922-9.

30. Yan TD, Black D, Sugarbaker PH, et al. A systematic review and meta-analysis of the randomized controlled trials on adjuvant intraperitoneal chemotherapy for resectable gastric cancer. Ann Surg Oncol 2007;14:2702-13.

31. Desiderio J, Chao J, Melstrom L, et al. The 30-year experience-A meta-analysis of randomised and high-quality non-randomised studies of hyperthermic intraperitoneal chemotherapy in the treatment of gastric cancer. Eur J Cancer 2017;79:1-14.

32. Bonnot PE, Piessen G, Kepenekian V, et al. Cytoreductive Surgery With or Without Hyperthermic Intraperitoneal Chemotherapy for Gastric Cancer With Peritoneal Metastases (CY'TO-CHIP study): A Propensity Score Analysis. J Clin Oncol 2019;37:2028-40.

33. Verbraecken J, Van de Heyning P, De Backer W, et al. Body surface area in normal-weight, overweight, and obese adults. A comparison study. Metabolism 2006;5 5:515-24.

34. Yu CY, Lo YH, Chiou WK. The 3D scanner for measuring body surface area: a simplified calculation in the Chinese adult. Appl Ergon 2003;34:273-8.

35. Kaibara N, Hamazoe R, Iitsuka Y, et al. Hyperthermic peritoneal perfusion combined with anticancer chemotherapy as prophylactic treatment of peritoneal recurrence of gastric cancer. Hepatogastroenterology 1989;36:75-8.

36. Koga S, Hamazoe R, Maeta M, et al. Prophylactic therapy for peritoneal recurrence of gastric cancer by continuous hyperthermic peritoneal perfusion with mitomycin C. Cancer 1988;61:232-7.

37. Hamazoe R, Maeta M, Kaibara N. Intraperitoneal thermochemotherapy for prevention of peritoneal recurrence of gastric cancer. Final results of a randomized controlled study. Cancer 1994;73:2048-52.

38. Ikeguchi M, Kondou A, Oka A, et al. Effects of continuous hyperthermic peritoneal perfusion on prognosis of gastric cancer with serosal invasion. Eur J Surg 1995;161:581-6.

39. Fujimoto S, Takahashi M, Mutou T, et al. Successful intraperitoneal hyperthermic chemoperfusion for the prevention of postoperative peritoneal recurrence in patients with advanced gastric carcinoma. Cancer 1999;85:529-34.

40. Yonemura Y, de Aretxabala X, Fujimura T, et al. Intraoperative chemohyperthermic peritoneal perfusion as an adjuvant to gastric cancer: final results of a randomized controlled study. Hepatogastroenterology 
2001;48:1776-82.

41. Cui HB, Ge HE, Bai XY, et al. Effect of neoadjuvant chemotherapy combined with hyperthermic intraperitoneal perfusion chemotherapy on advanced gastric cancer. Exp Ther Med 2014;7:1083-8.

42. Yonemura Y, Ninomiya I, Kaji M, et al. Prophylaxis with intraoperative chemohyperthermia against peritoneal recurrence of serosal invasion-positive gastric cancer. World J Surg 1995;19:450-4; discussion 5.

43. Hirose K, Katayama K, Iida A, et al. Efficacy of continuous hyperthermic peritoneal perfusion for the prophylaxis and treatment of peritoneal metastasis of advanced gastric cancer: evaluation by multivariate regression analysis. Oncology 1999;57:106-14.

44. Kunisaki C, Shimada H, Akiyama H, et al. Therapeutic outcomes of continuous hyperthermic peritoneal perfusion against advanced gastric cancer with peritoneal carcinomatosis. Hepatogastroenterology 2006;53:473-8.

45. Zhu ZG, Tang R, Yan M, et al. Efficacy and safety of intraoperative peritoneal hyperthermic chemotherapy for advanced gastric cancer patients with serosal invasion. A long-term follow-up study. Dig Surg 2006;23:93-102.

46. Kang LY, Mok KT, Liu SI, et al. Intraoperative hyperthermic intraperitoneal chemotherapy as adjuvant chemotherapy for advanced gastric cancer patients with serosal invasion. J Chin Med Assoc 2013;76:425-31.

47. Glehen O, Passot G, Villeneuve L, et al. GASTRICHIP: D2 resection and hyperthermic intraperitoneal chemotherapy in locally advanced gastric carcinoma: a randomized and multicenter phase III study. BMC Cancer 2014;14:183.

48. Kunisaki C, Shimada H, Nomura M, et al. Lack of efficacy of prophylactic continuous hyperthermic peritoneal perfusion on subsequent peritoneal recurrence and survival in patients with advanced gastric cancer. Surgery 2002;131:521-8.

49. Yang XJ, Huang CQ, Suo T, et al. Cytoreductive surgery and hyperthermic intraperitoneal chemotherapy improves survival of patients with peritoneal carcinomatosis from gastric cancer: final results of a phase III randomized

Cite this article as: Brandl A, Prabhu A. Intraperitoneal chemotherapy in the treatment of gastric cancer peritoneal metastases: an overview of common therapeutic regimens. J Gastrointest Oncol 2021;12(Suppl 1):S32-S44. doi: 10.21037/ jgo-2020-04 clinical trial. Ann Surg Oncol 2011;18:1575-81.

50. Rudloff U, Langan RC, Mullinax JE, et al. Impact of maximal cytoreductive surgery plus regional heated intraperitoneal chemotherapy (HIPEC) on outcome of patients with peritoneal carcinomatosis of gastric origin: results of the GYMSSA trial. J Surg Oncol 2014;110:275-84.

51. Fujimoto S, Takahashi M, Mutou T, et al. Improved mortality rate of gastric carcinoma patients with peritoneal carcinomatosis treated with intraperitoneal hyperthermic chemoperfusion combined with surgery. Cancer 1997;79:884-91.

52. Li C, Yan M, Chen J, et al. Surgical resection with hyperthermic intraperitoneal chemotherapy for gastric cancer patients with peritoneal dissemination. J Surg Oncol 2010;102:361-5.

53. Zhibing W, Qinghua D, Shenglin M, et al. Clinical study of cisplatin hyperthermic intraperitoneal perfusion chemotherapy in combination with docetaxel, 5-flourouracil and leucovorin intravenous chemotherapy for the treatment of advanced-stage gastric carcinoma. Hepatogastroenterology 2013;60:989-94.

54. Nakanishi H, Mochizuki Y, Kodera Y, et al. Chemosensitivity of peritoneal micrometastases as evaluated using a green fluorescence protein (GFP)-tagged human gastric cancer cell line. Cancer Sci 2003;94:112-8.

55. Yonemura Y, Endou Y, Tochiori S, et al. Effect of intraperitoneal chemotherapy on experimental peritoneal dissemination of gastric cancer. Gan To Kagaku Ryoho 2005;32:1635-9.

56. Nakamura M, Ojima T, Nakamori M, et al. Conversion Surgery for Gastric Cancer with Peritoneal Metastasis Based on the Diagnosis of Second-Look Staging Laparoscopy. J Gastrointest Surg 2019;23:1758-66.

57. Fujitani K, Yang HK, Mizusawa J, et al. Gastrectomy plus chemotherapy versus chemotherapy alone for advanced gastric cancer with a single non-curable factor (REGATTA): a phase 3, randomised controlled trial. Lancet Oncol 2016;17:309-18. 